\title{
DETERMINATION OF NEUTRON-INDUCED ACTIVATION CROSS SECTIONS USING NIRR-1
}

\author{
*Sadiq, U. ${ }^{1}$ Jonah, S.A. ${ }^{2}$ Nasiru, R. $^{1}$ and Zakari, Y.I. ${ }^{1}$ \\ ${ }^{1}$ Department of Physics, Ahmadu Bello University, Zaria \\ ${ }^{2}$ Reactor Engineering Section, Centre for Energy Research and Training, Ahmadu Bello University, Zaria \\ Correspondence author: sadiqumarx@yahoo.co.uk
}

\begin{abstract}
Thermal Activation cross-sections for the $(n, v)$ reaction were experimentally measured using NIRR-1 facilities. The irradiated target isotopes were ${ }^{71} \mathrm{Ga},{ }^{109} \mathrm{Ag},{ }^{55} \mathrm{Mn}{ }^{94} \mathrm{Zr} ;{ }^{96} \mathrm{Zr} ;{ }^{238} \mathrm{U},{ }^{74} \mathrm{Se},{ }^{75} \mathrm{As}$ and ${ }^{48} \mathrm{Ca}$. In order to obtain reliable activation cross sections, careful attention was paid to neutron irradiation and to the measurement of induced activity. The values obtained for the ten $(n, v)$ reactions were compared against the comprehensive evaluated values listed in Mughabghab, (2003) and other evaluated data libraries. The values were found to compare well with values evaluated by Mughabghab and those from other libraries.
\end{abstract}

Keywords: RNAA, Thermal capture cross section, Resonance integral, $k_{0}$-factors.

\section{INTRODUCTION}

A database of activation cross sections for neutron energies (of up to $20 \mathrm{MeV}$ ) is required for the design of a D-T fusion reactor, neutron dosimetry and neutron shielding in a reactor facility, and for confirming predictions based on reaction calculations. The $(n, y)$ cross section $\sigma_{0}$ is a basic constant and the reliability of the literature data should be a matter of concern; as the accuracy and consistency of $\sigma_{0}{ }^{\prime} \mathrm{s}$ from different libraries are often troublesome (De Corte et al, 1987) thus making a selection of reliable data difficult. A number of the cross section data compiled, in several evaluated data libraries, are evaluated mainly on the basis of theoretical calculations. Experimental data, if available, are used to normalize the calculated values and to improve their accuracy and reliability. In cases where no measurements have been made, the systematics for the majority of the reactions are used to predict the cross sections.

Recently, a number of investigations were conducted to measure activation cross sections $\sigma_{0}$ and isomeric cross section ratios $I_{0}$ of some nuclides whose $\sigma_{0}$ and $I_{0}$ are either doubtful or have never been measured (Andrej, 2002). More recently, the IAEA set up the Working Party on Evaluation Co-operation (WCEC) Subgroup-23 (SG-23) to assemble, verify and validate an evaluated data library for the minor fission products by reviewing and making use of existing evaluations, running nuclear model calculations and performing partial re-evaluation work (Andrej, 2002). The purpose of the exercise was to compare the thermal capture cross sections and resonance integrals from the SG-23 library to the equivalent values in the $k_{0}$ database. It was discovered that 12 out of 30 nuclides studied showed differences from $5 \%$ to greater than $20 \%$.

The Nigeria Research Reactor-1, NIRR1, is designed for use in NAA thus, its neutron flux remains stable and constant during both irradiations of the 'bare' and the 'Cd-covered' foils.. The $k_{0}$-standardized method is widely accepted for multi-element NAA with respect to variations in neutron spectrum parameters and gamma-ray counting geometry (De Corte, 1987). The $k_{0}$-standardized method, developed in the $1970 \mathrm{~s}$ by Simonits et al., (1975) involves the simultaneous irradiation of a sample and a neutron flux monitor, such as gold, and the use of a composite nuclear constant called $\mathrm{k}_{0}$-factor. The $k_{0}$-factor is independent of irradiation and measuring conditions thus, eliminating the problems of non-availability of standards for certain elements and the inaccuracy caused by poorly prepared in-house standards (Jonah et al, 2005). Our main objective is to determine activation cross section data in the framework of the IAEA Coordinated Research Project No.13728 entitled "Reference Database for NAA" using the NIRR-1 Facilities.

\section{MATERIALS AND METHODS}

In the $k_{0}$ standardization of NAA, the concentration of the analyte ' $a$ ' is obtained from its measured isotope/gamma ray as

$$
\rho_{a}=\frac{\left(N_{P} / W t_{m} S D C\right)_{a}}{\left(N_{P} / w t_{m} S D C\right)_{A u}} \times \frac{1}{k_{0, A u}(a)} \times \frac{f+Q_{0, A u}(\alpha)}{f+Q_{0, a}(\alpha)} \times \frac{\varepsilon_{P, A u}}{\varepsilon_{P, a}}
$$

where ' $\mathrm{Au}$ ' refers to the co-irradiated gold monitor $\left[{ }^{197} \mathrm{Au}(\mathrm{n}, \mathrm{Y}){ }^{198} \mathrm{Au}, \mathrm{E}_{\mathrm{Y}}=411.8 \mathrm{keV}\right]$ and $\mathrm{N}_{\mathrm{p}}$ is the number of counts in the full energy peak, $W$ the weight of the gold monitor, $\mathrm{W}$ the weight of the sample, S the saturation factor, D the decay factor, C the counting factor, $t_{d}$ the decay time, $t_{u r}$ the irradiation time, $t_{m}$ the measuring time, $f$ the thermal to epithermal neutron flux ratio, a the epithermal neutron flux distribution, approximated by a $1 / \mathrm{E}^{1+a}$ dependence, 
$\mathrm{Q}_{0}=\mathrm{I}_{\mathrm{o}} / \sigma_{\mathrm{o}}$ is the ratio of resonance integral to thermal neutron capture cross section at neutron velocity of 2200 $\mathrm{ms}^{-1}$ and $\varepsilon_{\mathrm{p}}$ the full energy peak detection efficiency.

Furthermore, in Eq. (1), the $\mathrm{k}_{0, \mathrm{Aa}}$ (a) factor is defined as

$$
k_{0, A u}(a)=\frac{M_{A u} \theta_{a} \sigma_{0, a} \gamma_{a}}{M_{a} \theta_{A u} \sigma_{0, A u} \gamma_{A u}}
$$

Where $M$ is the atomic weight, $\theta$ is the isotopic abundance, $\sigma_{0}$ is the $2200 \mathrm{~m} / \mathrm{s}(\mathrm{n}, \mathrm{y})$ cross section, and $\mathrm{y}$ is the absolute gamma ray intensity (emission probability).

Eq. (1) is written in the Hogdahl formalism (modified for a $1 / E^{1+a}$ epithermal flux shape for which it is required that the cross section in the thermal neutron region varies as $1 / v$. This requirement is fulfilled to a good approximation by most analytically interesting $(n, y)$ reactions.

The conversions from the $Q_{0}$ values to $Q_{0}(a)$ and from $s_{0}$ values to $s_{0}(a)$, is given by

$$
Q_{0}(\alpha)=\left[\frac{Q_{0}-0.429}{\left(\bar{E}_{r}\right)^{\alpha}}+\frac{0.429}{(2 \alpha+1)\left(E_{C d}\right)^{\alpha}}\right](1 \mathrm{eV})^{\alpha}
$$

where $\bar{E}_{r}$ is the effective resonance energy. The $(1 \mathrm{eV})^{a}$ term (numerically unity) originates from the definition of the epithermal neutron flux in a $1 / E^{1+a}$ distribution. The above treatise holds for the case where the analytical isotope is directly formed by $(n, y)$ reaction.

As to the measurement of $Q_{0}$ values, the well-known cadmium ratio method (in the Hogdahl formalism) was used, and

$$
Q_{0}(\alpha)=\frac{f}{F_{C d} R_{C d}-1}
$$

followed by conversion of $\mathrm{Q}_{0}$ (a) to $\mathrm{Q}_{0}$ according to Eq. (3)

\section{Experimental}

The neutron-induced nuclear reactions, whose activation cross sections were measured include:- ${ }^{71} \mathrm{Ga}$ $(\mathrm{n}, \mathrm{Y})^{72} \mathrm{Ga} ;{ }^{109} \mathrm{Ag}(\mathrm{n}, \mathrm{Y})^{110 \mathrm{~m}} \mathrm{Ag} ;{ }^{55} \mathrm{Mn}(\mathrm{n}, \mathrm{Y})^{56} \mathrm{Mn}$; ${ }^{94} \mathrm{Zr}(\mathrm{n}, \mathrm{\gamma}){ }^{95} \mathrm{Zr} ;{ }^{96} \mathrm{Zr}(\mathrm{n}, \mathrm{y}){ }^{97} \mathrm{Zr} ;{ }^{238} \mathrm{U}(\mathrm{n}, \mathrm{y}){ }^{239} \mathrm{U} ;{ }^{74} \mathrm{Se}$ $(\mathrm{n}, \mathrm{y}){ }^{75} \mathrm{Se} ;{ }^{75} \mathrm{As}(\mathrm{n}, \mathrm{y}){ }^{76} \mathrm{As} ; \quad{ }^{48} \mathrm{Ca}(\mathrm{n}, \mathrm{y}){ }^{49} \mathrm{Ca}$. The thermal cross sections $\sigma_{0}$; resonance integrals, $\mathrm{I}_{0}$, or the ratio of resonance integrals to thermal cross sections $Q_{0}$, from references, (Andrej, 2002) show large differences of between $5-20 \%$.

The description of the monitors and the nuclear data of the reactions measured or reevaluated are as given in Tables 1 and 2.

Table 1: Description of monitor foils and oxides used.

\begin{tabular}{|c|c|c|c|c|c|c|c|}
\hline Atomic Weight & Target & product & $\mathbf{T}_{1 / 2}$ & $E_{r}$ & $\theta, \%$ & $E_{\mathbf{p}}, \mathbf{k e V}$ & $Y, \%$ \\
\hline \multirow[t]{7}{*}{74.92} & ${ }^{75}$ As & ${ }^{76} \mathrm{As}$ & $26.32 \mathrm{~h}$ & 106 & 100 & 559.1 & 44.6 \\
\hline & & & & & & 559.2 & 46.2 \\
\hline & & & & & & 563.2 & 1.6 \\
\hline & & & & & & 657.1 & 6.4 \\
\hline & & & & & & 1212.9 & 1.8 \\
\hline & & & & & & $1212.9+1216.1$ & 5.5 \\
\hline & & & & & & 1216.1 & 3.7 \\
\hline 196.97 & ${ }^{197} \mathrm{Au}$ & ${ }^{198} \mathrm{Au}$ & $2.695 d$ & 5.65 & 100 & 411.8 & 95.53 \\
\hline \multirow[t]{3}{*}{54.94} & ${ }^{55} \mathrm{Mn}$ & ${ }^{56} \mathrm{Mn}$ & $2.579 \mathrm{~h}$ & 468 & 100 & 846.8 & 99 \\
\hline & & & & & & 1810.7 & 27.2 \\
\hline & & & & & & 2113.1 & 14.3 \\
\hline 91.22 & ${ }^{95} \mathrm{Zr}$ & ${ }^{96} \mathrm{Zr}$ & $34.97 d$ & 6260 & 17.28 & 765.8 & 99 \\
\hline
\end{tabular}

\begin{tabular}{clcc}
\hline Target & Material description & $\begin{array}{c}\text { Diameter, } \\
\text { cm }\end{array}$ & $\begin{array}{c}\text { Range } \\
\text { mass, mg }\end{array}$ \\
\hline $\mathrm{Au}$ & $\mathrm{Al}-0.1 \% \mathrm{Au} ;$ 0.1mm thick, IRMM-530 & 0.8 & $12-14$ \\
$\mathrm{Mn}$ & $\mathrm{Mn}-1 \%$ Al foil, 0.1mm thick, SP89070 IRMM. & 0.6 & $3-5$ \\
$\mathrm{Zr}$ & $99.8 \% \mathrm{Zr}$ foil; 1mm thick, Goodfellow & 0.6 & $42-45$ \\
$\mathrm{U}$ & $\mathrm{U}-0.2 \%$ Al foil, 0.1mm thick, NS2017 IRMM. & 0.6 & $43-53$ \\
$\mathrm{Se}$ & $\mathrm{SeO}_{2}$ powder, Merck KGaA & - & $51-63$ \\
$\mathrm{Ag}$ & $\mathrm{Ag}_{2} \mathrm{O}$ powder, Merck KGaA & - & $50-51$ \\
$\mathrm{Ga}$ & $\mathrm{Ga}_{2} \mathrm{O}_{3}$ powder, Riedel-de-Haën. & - & $52-62$ \\
$\mathrm{Ca}$ & $\mathrm{CaO}_{2}$ powder, Merck KGaA & - & $54-57$ \\
$\mathrm{As}$ & $\mathrm{As}_{2} \mathrm{O}_{3}$ powder, Riedel-de-Haën. & - & $52-54$ \\
\hline
\end{tabular}

Table 2: uclear data of monitor foils and oxides used. 
Bajopas Volume 3 Number 1 June 2010

Table 2 Continue

\begin{tabular}{|c|c|c|c|c|c|c|c|}
\hline \multicolumn{2}{|c|}{ Atomic Weight } & \multirow{2}{*}{$\begin{array}{c}\text { Target } \\
{ }^{239} \mathrm{U}\end{array}$} & \multirow{2}{*}{$\begin{array}{c}\text { product } \\
23.45 \mathrm{~m}\end{array}$} & \multirow{2}{*}{$\begin{array}{r}\mathbf{T} 1 / 2 \\
16.9\end{array}$} & \multirow{2}{*}{$\begin{array}{c}\boldsymbol{\theta}, \% \\
99.2746\end{array}$} & \multirow{2}{*}{$\begin{array}{r}\text { Ey, keV } \\
74.7\end{array}$} & \multirow{2}{*}{$\begin{array}{ll} & \mathbf{Y}, \% \\
50 & \end{array}$} \\
\hline 238.03 & $238 \mathrm{U}$ & & & & & & \\
\hline \multirow[t]{5}{*}{78.96} & ${ }^{74} \mathrm{Se}$ & ${ }^{75} \mathrm{Se}$ & $119.8 \mathrm{~d}$ & 29.4 & 0.9 & 121.1 & 16.41 \\
\hline & & & & & & 136 & 56.02 \\
\hline & & & & & & 264.7 & 58.6 \\
\hline & & & & & & 279.5 & 24.73 \\
\hline & & & & & & 400.7 & 11.13 \\
\hline \multirow[t]{15}{*}{107.87} & ${ }^{109} \mathrm{Ag}$ & ${ }^{110 \mathrm{~m}} \mathrm{Ag}$ & $249.76 d$ & 6.08 & 48.17 & 446.8 & 3.657 \\
\hline & & & & & & 620.4 & 2.776 \\
\hline & & & & & & 657.8 & 94.74 \\
\hline & & & & & & 677.6 & 10.8621 \\
\hline & & & & & & 687 & 6.49 \\
\hline & & & & & & 706.7 & 17.0242 \\
\hline & & & & & & 744.3 & 4.661 \\
\hline & & & & & & 763.9 & 22.36 \\
\hline & & & & & & 818 & 7.323 \\
\hline & & & & & & 884.7 & 72.86 \\
\hline & & & & & & 937.5 & 34.31 \\
\hline & & & & & & 1384.3 & 24.35 \\
\hline & & & & & & 1475.8 & 3.989 \\
\hline & & & & & & 1505 & 13.11 \\
\hline & & & & & & 1562.3 & 1.184 \\
\hline \multirow{8}{*}{69.72} & ${ }^{71} \mathrm{Ga}$ & ${ }^{72} \mathrm{Ga}$ & $14.1 \mathrm{~h}$ & 154 & 39.9 & 630 & 24.37 \\
\hline & & & & & & 834 & 99.55 \\
\hline & & & & & & 894.2 & 9.842 \\
\hline & & & & & & 1050.7 & 6.921 \\
\hline & & & & & & 2201.7 & 26.06 \\
\hline & & & & & & 2491 & 7.472 \\
\hline & & & & & & 2501.8 & 20.52 \\
\hline & & & & & & 2507.9 & 13.05 \\
\hline 40.08 & ${ }^{48} \mathrm{Ca}$ & ${ }^{49} \mathrm{Ca}$ & $8.718 \mathrm{~m}$ & 1330000 & 0.187 & 3084.4 & 91.7 \\
\hline
\end{tabular}

Source: DeCorte et al. (986)



Fig.1. Graphical comparis on of Mughabghab with our result and other evaluated data 
Table 3: Comparison of Calculated Activation cross section $\sigma_{0}$ and libraries.

\begin{tabular}{ccccccc}
\hline Target & Product & Mughabghab & SG-23 & $\mathbf{k}_{\mathbf{0}} /$ Nudat & Jendl & This work \\
\hline${ }^{197} \mathrm{Au}$ & ${ }^{198} \mathrm{Au}$ & $98.65 \pm 0.09$ & - & - & - & $98.74 \pm 0.10$ \\
${ }^{94} \mathrm{Zr}$ & ${ }^{95} \mathrm{Zr}$ & $0.0499 \pm 0.0024$ & 0.04992 & 0.051 & 0.04981 & $0.0433 \pm 0.01$ \\
${ }^{96} \mathrm{Zr}$ & ${ }^{97} \mathrm{Zr}$ & $0.0229 \pm 0.001$ & 0.02118 & 0.0197 & 0.0228 & $0.0213 \pm 0.01$ \\
${ }^{238} \mathrm{U}$ & ${ }^{239} \mathrm{U}$ & $2.68 \pm 0.019$ & $2.75 *$ & - & 2.717 & $2.7252 \pm 0.03$ \\
${ }^{55} \mathrm{Mn}$ & ${ }^{56} \mathrm{Mn}$ & $13.36 \pm 0.05$ & $13.2 *$ & - & 13.41 & $13.3055 \pm 0.14$ \\
${ }^{109} \mathrm{Ag}$ & ${ }^{110 m} \mathrm{Ag}$ & $4.7 \pm 0.20$ & $3.90 *$ & - & 90.53 & $4.2403 \pm 0.26$ \\
${ }^{48} \mathrm{Ca}$ & ${ }^{49} \mathrm{Ca}$ & $1.09 \pm 0.07$ & $1.12 *$ & - & 1.093 & $0.8502 \pm 0.24$ \\
${ }^{71} \mathrm{Ga}$ & ${ }^{72} \mathrm{Ga}$ & $4.73 \pm 0.15$ & $4.735(1.8)$ & $4.650(0.8)$ & 3.709 & $4.7857 \pm 0.05$ \\
${ }^{74} \mathrm{Se}$ & ${ }^{75} \mathrm{Se}$ & $51.8 \pm 1.2$ & $51.86(2.7)$ & $50.50(4.8)$ & 51.8 & $77.418 \pm 9.14$ \\
${ }^{75} \mathrm{As}$ & ${ }^{76} \mathrm{As}$ & $4.23 \pm 0.08$ & $4.092(6.3)$ & $3.85(4.8)$ & 4.5 & $4.3776 \pm 0.03$ \\
\hline
\end{tabular}

\section{RESULTS AND DISCUSSIONS}

For these determinations, the cadmium ratio was used. The nuclear data for the nuclides used and the cross section for gold, which is the universal comparator, were taken from DeCorte et al., (2003). The resulting activation cross sections of the $10(n, y)$ reactions obtained were compared to the evaluated values by Mughabghab, 2003, the SG-23 library, $2002, \mathrm{k}_{0} /$ Nudat as well as other nuclear data libraries and is as presented in Table 3 and discussed in 1 to 10 below.

1. ${ }^{197} \mathrm{Au}(\mathrm{n}, \mathrm{y}){ }^{198} \mathrm{Au}$ reaction.

Though this is not among the reactions whose activation cross section is in doubt, but our result is in excellent agreement with the evaluated data from the nuclear data libraries, SG-23 and Mughabghab within a range of $0.1 \%$.

2. ${ }^{94} \mathrm{Zr}(\mathrm{n}, \mathrm{y}){ }^{95} \mathrm{Zr}$ reaction.

Although the evaluated data from the libraries and Mughabghab agree with our results to within $13 \%$, the values from the different libraries agree with each other to within almost the same margin.

3. ${ }^{96} \mathrm{Zr}(\mathrm{n}, \mathrm{y}){ }^{97} \mathrm{Zr}$ reaction.

Our result completely agrees with the results of the SG-23 but differ slightly with results from JENDL-3.3 and Mughabghab to within $7 \%$. The $\mathrm{k}_{0}$-Nudat value differs from JENDL3.3 and Mughabghab by about $14 \%$.

4. $\quad{ }^{238} U(n, y){ }^{239} U$ reaction.

Our result completely agrees with the evaluated data reported in the libraries and are also in excellent agreement with Mughabghab within a range of $2 \%$

5. $\quad{ }^{55} \mathrm{Mn}(\mathrm{n}, \mathrm{y}){ }^{56} \mathrm{Mn}$ reaction.

The evaluated data reported by Mughabghab are in agreement with our results to within $0.4 \%$. The results from JENDL-3.3 also differ from Mughabghab by about the same margin.
6.

${ }^{109} \mathrm{Ag}(\mathrm{n}, \mathrm{y}){ }^{110 \mathrm{~m}} \mathrm{Ag}$ reaction.

The evaluated data reported by Mughabghab is in agreement with our result to within $10 \%$., but differs significantly from results listed by JENDL-3.3.

7. $\quad{ }^{48} \mathrm{Ca}(\mathrm{n}, \mathrm{y}){ }^{49} \mathrm{Ca}$ reaction.

The evaluated data reported by Mughabghab and JENDL-3.3 vary significantly with our results to within $22 \%$. The results from IAEATECDOC, 1990 also differ from our results by about $26 \%$.

8. $\quad{ }^{71} \mathrm{Ga}(\mathrm{n}, \mathrm{y}){ }^{72} \mathrm{Ga}$ reaction.

The evaluated data reported by Mughabghab and the other nuclear data libraries are in excellent agreement with our results to within $1.2 \%$. Only the results from JENDL-3.3 differ from our result by about $22 \%$.

9. $\quad{ }^{74} \mathrm{Se}(\mathrm{n}, \mathrm{y}){ }^{75} \mathrm{Se}$ reaction.

The most significant difference from evaluated data reported by Mughabghab and the other nuclear data libraries is in this reaction, where the agreement with our results is to within $49 \%$.

10. ${ }^{75}$ As $(n, y){ }^{76}$ As reaction.

The evaluated data reported by Mughabghab and JENDL-3.3 are in excellent agreement with our results to within $3.5 \%$. The results from SG-23 and $\mathrm{k}_{0}$-Nudat differ from our result by about $7 \%$ and $14 \%$ respectively.

A graphical comparison of our results with reported values from evaluated data libraries is also presented in Figure 1 . The $\mathrm{k}_{0}$-values for the various gamma energies of these 10 isotopes were also calculated and presented along with the other calculated parameters as shown in Table 3. The results also compare favorably with the evaluated values by Mughabghab and other compilations by De Corte et al, 2003. A graphical comparison of our values with Mughabghab is also given in Figure 1. 


\section{CONCLUSION}

The cadmium ratio was used to determine the thermal cross sections of ten ( $n, y)$ reactions. Using the reaction ${ }^{197} \mathrm{Au}(\mathrm{n}, \mathrm{y}){ }^{198} \mathrm{Au}$ as the standard, the results from seven of the nine reactions were found to be in

\section{REFERENCES}

Andrej, T.(2002): Validation of thermal cross sections and resonance integrals of SG-23 evaluated nuclear data library; SG-23_ validation doc., IAEA.

De Corte F.; Simonits, A.; De Wispelaere, A.; Hoste, J.; (1986): Compilation of $\mathrm{k}_{0}$-factors and related nuclear data for 94 radionuclides of interest in NAA.; INW/KFKI interim report(1986)

De Corte, F. (1987): The $k_{0}$ - Standardization Method A Move to the Optimization of NAA; Ph.D Thesis; University of Gent, Belgium

De Corte F.; Simonits, A.; De Wispelaere, A.; Hoste, J.; (1987): Accuracy and applicability of $k_{0}$ standardization method, Journal of Radioanalytical Chemistry, vol. 113, pp145161.

De Corte F.; Simonits, A. (2003): Recommended Nuclear Data for Use in the $k_{0}$ Standardization of Neutron Activation Analysis: Atomic Data and Nuclear Data Tables 85, pp.47-67.

IAEA TECDOC, (1990): Practical aspects of operating a neutron activation analysis Laboratory; International Atomic Energy Agency IAEATEC DOC 564. excellent agreement to within $7 \%$ of those reported from evaluated data libraries. The results from the reactions ${ }^{48} \mathrm{Ca}(\mathrm{n}, \mathrm{y}){ }^{49} \mathrm{Ca}$ and ${ }^{74} \mathrm{Se}(\mathrm{n}, \mathrm{y}){ }^{75} \mathrm{Se}$, were found to differ significantly ( $22 \%$ and $49 \%$ ) from the evaluated data libraries.

Jonah, S.A.; Balogun, G.I.; Umar, I.M.; Mayaki, M. C. (2005): Neutron spectrum parameters in irradiation channels of the Nigeria Research Reactor-1 (NIRR-1) for the $\mathrm{k}_{0}$-NAA standardization. Journal of Radioanalytical and Nuclear Chemistry, Vol. 266, No. 1, p 8388 .

Mughabghab, S. F. (2003): Thermal neutron capture cross sections, resonance integrals and gfactors; International Atomic Energy Agency, INDC (NDS) -440

Shibata, K., Kawano, T., Nakagawa, T., Iwamoto, O., Katakura, J. Fukahori, T., Chiba, S., Hasegawa, A., Murata, T., Matsunobu, H., Ohsawa, T., Nakajima, T., Yoshida, T., Zukeran, A., Kawai, M., Baba, M., Ishikawa, M., Asami, T., Watanabe, Y., Igashira, N., Yamamuro, N., Kitazawa, H., Yamano, N., Takano, H., (2002): Japanese Evaluated Nuclear Data Library Version 3- Revision 3: JENDL-3.3, Nucl. Sci. Technol. 39, 1125

Simonits, A.; De Corte, F.; Hoste, J.; (1975): Single comparator methods in reactor neutron activation analysis; Journal of Radioanalytical and Nuclear Chemistry,24 pp.31-46. 